\title{
Paediatric Early Warning Scores: Holy Grail and Achilles' Heel
}

Author: Dr. Damian Roland

Paediatric Emergency Medicine Leicester Academic (PEMLA) Group

c/o Elizabeth Cadman-Moore, Emergency Department Secretaries

Emergency Department, Leicester Royal Infirmary

Leicester,

LE1 5WW

e-mail: dr98@le.ac.uk

phone: 01162586397 (no answer phone)

mobile: 07727158213

This report is independent research arising from a Doctoral Research Fellowship supported by the National Institute for Health Research. The views expressed in this publication are those of the author(s) and not necessarily those of the NHS, the National Institute for Health Research or the Department of Health 


\section{Introduction}

The reliable identification of the critically ill or deteriorating child has been both the Holy Grail and Achilles' heel of paediatric practice for some time. It is well recognised that paediatric in-patients who die or subsequently require intensive care often show signs of physiological and behavioural disturbance prior to arrest or collapse[1]. As a result one of the recommendations in the Confidential Enquiry into Maternal and Childhood report "Why Children Die" stated:

\section{"For paediatric care in hospital we recommend a standardised and rational monitoring system with imbedded early identification systems for children developing critical illness - an early warning score".[2]}

The NPSA "Review of patient safety for children and young people" in 2009 supported this view [3] as have the National Institute for Clinical Excellence [4]. In the UK it is therefore incumbent on providers of inpatient paediatric services to review their monitoring systems. The important of this is highlighted by the NHS outcomes framework which contains a specific indicator "Incidence of harm to children due to 'failure to monitor' [5]. A cross sectional survey of United Kingdom (UK) hospitals in 2005 found only a small proportion of units were using them. The questionnaire determined,

"that 21.5\% of the 144 NHS Trusts that care for children as inpatients have an early warning system, but there is no consistency of approach" [6]

A lack of definition of true purpose and anecdotal reports they increase workload rather than improve patient safety has often created mistrust in their use. Reciprocally the increasing use of short stay units and pressures on out- of- hours services have prompted their introduction in acute assessment areas although in this context they may be considered serious illness identification aids rather than true "early warning" scores.

It is important for patient safety, clinical governance and for health care professional education that all units have established mechanisms by which children who require enhanced care can be easily recognised. One such, but not the only, mechanism is an early warning score (EWS). Although relevant literature will be discussed this article is not intended to be a systematic review of EWS as this has been recently performed [7]. The aim is to describe the background to their development and identify common issues to provide information for units interested in introducing an EWS into their department. The term EWS in this article refer to paediatric systems unless stated in the text.

\section{Background Information}

\subsection{The First Scoring Systems}

It may be considered that triage was the first real use of a 'score' based system to identify illness. However in its original context it was used to identify those individuals, out of a large amount of casualties, who needed the most urgent intervention. Adult and Paediatric EWS represent a means of identifying deterioration in those already deemed 
to have some medical need and therefore are different from triage (Table One). Whether they are relevant to illness identification at initial point of contact is not something that has been clearly delineated. If we are expansive in our inclusion of such systems one of the earliest scores to be published was the Yale system developed by McCarthy et al. In the early eighties he created an observation scale to identify serious illness in febrile children and identified six observational items (Table Two) that were independent predictors of serious illness[8]. The latter defined as the culture of a bacterial pathogen in normally sterile tissue culture or any abnormalities of electrolytes, chest radiographs or blood gases. In this United States primary care cohort $11.9 \%$ (37/312) patients aged less than 24 months were subsequently found to have serious illness. The initial Yale score had a sensitivity of $77 \%$, specificity of $88 \%$, and a positive predictive value of $56 \%$ i.e just over $20 \%$ of children had a serious illness when the Yale Score predicted there should be none. Of note no child who smiled normally in this study had a serious illness.

The use of sensitivity and specificity to describe EWS and other measures of illness identification is often performed. However to meaningfully compare studies the outcomes must be identical and the overall incidence of disease measured. In Chapman et al's. systematic review [7] values of false negative rates were between $10-22 \%$ and it was noted a number of studies failed to or incorrectly calculated the figures.

\section{Table One}

\section{Different types of Scoring System}

\begin{tabular}{|l|l|}
\hline Triage & $\begin{array}{l}\text { This is a technique to determine, in a rapid fashion, the } \\
\text { priority in which a patient must be seen. It was } \\
\text { originally used during mass casualty events where } \\
\text { there may be very well and very unwell patients. } \\
\text { Technically it is therefore NOT an early warning } \\
\text { system as it validated to determine the speed in which } \\
\text { a patient must be seen. }\end{array}$ \\
\hline Illness Identification Systems & $\begin{array}{l}\text { These use individual patient characteristics (or } \\
\text { combinations of characteristics) to define a risk a } \\
\text { patient may have of a specific condition. This } \\
\text { commonly applies to serious bacterial illness but, for } \\
\text { example, may also be used in outcome prediction on } \\
\text { admission to Paediatric Intensive Care Units. }\end{array}$ \\
\hline Early Warning Scores & $\begin{array}{l}\text { Traditionally these are used on hospital wards to } \\
\text { identify (already unwell children) who are at risk of } \\
\text { deterioration to prevent intensive care admission or } \\
\text { cardio-respiratory arrest }\end{array}$ \\
\hline
\end{tabular}

The Yale study's wide inclusion criteria for serious illness, and that fact that it was not designed as an EWS in the conventional sense, means it is not validated for in-hospital 
use today. It does however form the back bone for the NICE Feverish illness in Children Guideline. The high incidence rate of serious illness in the Yale Study was in a primary care group who you would have expected to have had a lower pre-test probability of serious illness than a hospital cohort. The european research network on recognising serious infection investigators (ERNIE) highlighted the importance of understanding the effect pre-test probability has on the function of illness identification [9]. Although they were not specifically looking at EWS you can imagine that a tool identifying patients based on a post operative recovery ward following grommet surgery maybe at a lesser risk and type of deterioration than those following emergency surgery. The utility of the score therefore being very dependent on the characteristics of the population it is being used on.

Table Two - The Initial Yale Score

\begin{tabular}{|c|c|c|c|}
\hline $\begin{array}{l}\text { Observation } \\
\text { Item }\end{array}$ & $\begin{array}{c}1 \\
\text { Normal }\end{array}$ & $\begin{array}{c}3 \\
\text { Moderate } \\
\text { Impairment } \\
\end{array}$ & $\begin{array}{c}5 \\
\text { Severe Impairment }\end{array}$ \\
\hline Quality of Cry & $\begin{array}{l}\text { Strong with } \\
\text { normal tone OR } \\
\text { Content and not } \\
\text { crying }\end{array}$ & $\begin{array}{l}\text { Whimpering or } \\
\text { Sobbing }\end{array}$ & $\begin{array}{l}\text { Weak OR Moaning OR High } \\
\text { Pitched }\end{array}$ \\
\hline $\begin{array}{l}\text { Reaction to parent } \\
\text { stimulation }\end{array}$ & $\begin{array}{l}\text { Cries briefly } \\
\text { then stops OR } \\
\text { Content and not } \\
\text { crying }\end{array}$ & Cries off and on & $\begin{array}{l}\text { Continual Cry OR Hardly } \\
\text { responds }\end{array}$ \\
\hline State Variation & $\begin{array}{l}\text { If awake stays } \\
\text { awake OR if } \\
\text { asleep and } \\
\text { stimulated } \\
\text { wakes up } \\
\text { quickly }\end{array}$ & $\begin{array}{l}\text { Eyes close briefly OR } \\
\text { awakes with } \\
\text { prolonged } \\
\text { stimulation }\end{array}$ & $\begin{array}{l}\text { Falls to sleep OR will not } \\
\text { rouse }\end{array}$ \\
\hline Colour & Pink & $\begin{array}{l}\text { Pale extremities or } \\
\text { Acrocyanosis }\end{array}$ & $\begin{array}{l}\text { Pale OR Cyanotic OR } \\
\text { Mottled OR Ashen }\end{array}$ \\
\hline Hydration & $\begin{array}{l}\text { Skin normal, } \\
\text { eyes normal } \\
\text { AND mucous } \\
\text { membranes } \\
\text { moist }\end{array}$ & $\begin{array}{l}\text { Skin, eyes - normal } \\
\text { AND mouth slightly } \\
\text { dry }\end{array}$ & $\begin{array}{l}\text { Skin doughy OR tented } \\
\text { AND dry mucous } \\
\text { membranes AND/OR } \\
\text { sunken eyes }\end{array}$ \\
\hline $\begin{array}{l}\text { Response (talk, } \\
\text { smile) to social } \\
\text { overtures }\end{array}$ & $\begin{array}{l}\text { Smiles OR } \\
\text { Alerts }(<2 \mathrm{mo})\end{array}$ & $\begin{array}{l}\text { Brief smile OR Alerts } \\
\text { briefly }(<2 \mathrm{mo})\end{array}$ & $\begin{array}{l}\text { No smile OR Face anxious, } \\
\text { dull or expressionless OR } \\
\text { No alerting }(<2 \mathrm{mo})\end{array}$ \\
\hline
\end{tabular}

Source: McCarthy PL, Sharpe MR, Spiesel SZ, et al. Observation scales to identify serious illness in febrile children [8] 
A decade after the Yale score Morley et al. developed the Baby Check score[10]. This system was designed to detect serious illness in infants under six months old. It has been validated in settings outside its initial location of use including countries beyond the UK. However those who have attempted to develop EWS soon discover that controlling for variation in physiology as you grow older makes the creation of an age unifying chart problematic. This may explain the reason following the Yale and Baby Check publications there seemed to be a nadir in published scoring systems for children.

\subsection{The adult experience}

It wasn't until in adult practice there was increasing realisation that patients were dying on hospital wards with potential warning signs being present nearly 24 hours before their deaths[11] that national guidance began to appear. In 2003 the NHS modernisation agency[12] coined the term "Track and Trigger system" to bring together all the possible types of EWS that existed at that time. This was followed by NICE guidance[4] on managing the acutely ill adult in hospital which contained some definitions regarding the different types of track and trigger systems available (table three). An RCP report clearly found in favour of EWS and recommended an NHS warning score be used nationally in adult practice[13] although this has been challenged due the large heterogeneity of the population it is used on[14].

\section{Table Three}

\section{The NICE group divided known Track and Trigger Systems into four categories:}

\begin{tabular}{|l|l|}
\hline Single parameter system & $\begin{array}{l}\text { Periodic observation of selected vital signs that } \\
\text { are compared with a simple set of criteria with } \\
\text { predefined thresholds, with a response algorithm } \\
\text { being activated when any criterion is met. }\end{array}$ \\
\hline Multiple parameter system & $\begin{array}{l}\text { Response algorithm requires more than one } \\
\text { criterion to be met, or differs according to the } \\
\text { number of criteria met. }\end{array}$ \\
\hline Aggregate scoring system & $\begin{array}{l}\text { Weighted scores are assigned to physiological } \\
\text { values and compared with predefined trigger } \\
\text { thresholds. }\end{array}$ \\
\hline Combination system & $\begin{array}{l}\text { Single or multiple parameter systems used in } \\
\text { combination with aggregate weighted scoring } \\
\text { systems. }\end{array}$ \\
\hline
\end{tabular}

Source: NICE. Acutely ill patients in hospital: Recognition and response to acute illness in adults in hospitals [4]

\section{Development of Children's systems}

One of the first UK children's studies aiming to improve early medical staff review in the potentially deteriorating patient was by Monaghan whose "Brighton Score" was a combination system[15] [Table Four] 
The evidence validating its use was not particularly strong (the original audit contained only 30 patients who had triggered the system and there is no clear data presented on re-audit). However it is testament to the simplicity of the system that a version of the Brighton score is used in trusts outside of Brighton [16] with the score continuing to undergo validation. Monaghan notes in the paper, "Some staff could not see why we needed a score as they felt they were quite capable of recognising patients at risk". Implementation was also exacerbated by the additional paperwork that the score required on top of the normal observation chart (this was solved by incorporating the score into it). Engagement with staff is vital to ensure compliance, the introduction of an EWS at the Royal Free Hospital (London, UK) required over 16 iterations of a chart to be produced before a final version was agreed on (Personal Communication Sebastian Yuen, 2011) [Figure one - attached file].

\section{Table Four}

\section{The Brighton Score}

\begin{tabular}{|c|c|c|c|c|c|}
\hline & $\overline{0}$ & 1 & 2 & 3 & Score \\
\hline Behaviour & Playing/Appropriate & Sleeping & Irritable & $\begin{array}{l}\text { Lethargic/confused } \\
\text { Reduced response } \\
\text { to pain }\end{array}$ & \\
\hline Cardiovascular & $\begin{array}{l}\text { Pink or Capillary } \\
\text { Refill Time 1-2 s }\end{array}$ & $\begin{array}{l}\text { Pale or } \\
\text { Capillary Refill } \\
\text { Time } 3 \mathrm{~s}\end{array}$ & $\begin{array}{l}\text { Grey or } \\
\text { capillary refill } 4 \\
\text { seconds. } \\
\text { Tachycardia of } \\
20 \text { above } \\
\text { normal rate }\end{array}$ & $\begin{array}{l}\text { Grey and mottled } \\
\text { or capillary refill } 5 \\
\text { seconds or above. } \\
\text { Tachycardia of } \\
30 \text { above normal } \\
\text { rate or } \\
\text { bradycardia. }\end{array}$ & \\
\hline Respiratory & $\begin{array}{l}\text { Within normal } \\
\text { parameters, no } \\
\text { recession or } \\
\text { tracheal tug }\end{array}$ & $\begin{array}{l}>10 \text { above } \\
\text { normal } \\
\text { parameters, } \\
\text { using accessory } \\
\text { muscles, } 30 \%+ \\
\mathrm{FiO}_{2} \text { or } \\
6+\text { Litres } / \mathrm{min}\end{array}$ & $\begin{array}{l}>20 \text { above } \\
\text { normal } \\
\text { parameters } \\
\text { recessing, } \\
\text { tracheal } \\
\text { tug. } 40+\% \text { Fi02 } \\
\text { or } 6+ \\
\text { litres } / \mathrm{min}\end{array}$ & $\begin{array}{l}5 \text { below normal } \\
\text { parameters with } \\
\text { sternal } \\
\text { recession, tracheal } \\
\text { tug or } \\
\text { grunting. 50\% Fi02 } \\
\text { or } 8+ \\
\text { litres/min }\end{array}$ & \\
\hline
\end{tabular}

Source: Monaghan A. Detecting and managing deterioration in children [15]

At a similar time researchers in Australia[17] showed (without definitive statistical significance) the benefits of a medical emergency team (MET) to prevent cardiac arrest and death in an inpatient paediatric population. This study used nurse and doctor "worry" and range of physiological parameters as triggers.

\subsection{Problems with EWS}

It will always be difficult to quantify the effect the medical emergency team has over and above the education obtained from knowing that there is a team and what the criteria to call them are. Obviously controlling for this effect is extremely difficult. The Australian paper [17] demonstrated the low incidence of mortality in children $((0.19 / 1000)$ and hence the problem in using this as a relevant outcome measure. Despite this research on a MET being activated by an EWS has been replicated positively in other studies[18]. Tibballs et al [19] have recently looked specifically at systems to 
prevent in hospital arrest which shows a trend (both significant and non-significant) towards a reduction in cardio-pulmonary arrests in the studies reviewed. He notes that

"The key feature of a system is empowerment of any staff, including junior nurses and doctors and parents of children, to summon help without deferring to senior colleagues or to medical staff." [z]

Unfortunately there is also the confounder of generally increasing standards of care as time goes on. A recent publication demonstrated a natural improvement in mortality without any system in place at all[20]. Joffe et al. compared mortality data in a hospital without a MET with data from studies during a similar time period and concluded there was little difference. The research team hypothesised that a number of links are needed to effectively capture the deteriorating child [Table Five]:

\section{Table Five}

\section{Chain of events needed to demonstrate an improved response to deterioration in in-patient children}

(1) Symptoms and signs of deterioration ("calling criteria") occur and are recognized by ward personnel;

(2) The ward personnel are empowered to call for assistance without delay, circumventing established hier-archies if necessary;

(3) A readily available urgent response occurs; and

(4) This response, along with associated interventions, improves outcomes

Source: Joffe AR, Anton NR, Burkholder SC. Reduction in Hospital Mortality Over Time in a Hospital Without a Pediatric Medical Emergency Team: Limitations of Before-andAfter Study Designs [20]

From 2005 onwards there was an explosion of abstracts and papers on Paediatric Early Warning systems. The Plymouth[21] and subsequent Bristol[22] systems were designed to be used by all staff to identify children needing PICU intervention as audits had demonstrated key critical signs were being ignored. Their charts followed an ABCDE approach [Figure Two attached file].

Centres in Birmingham[23] and Yorkshire[24] used the Delphi method to design EWS which were subsequently validated. The Cardiff system has undergone a prospective evaluation and also applied the Australian MET system to its own unit[25, 26]. In both the Cardiff studies the systems had reasonable sensitivities but at the cost of low specificity and positive predictive value i.e few critically children were missed but a number of children activated unnecessarily. In these studies a number of children with completely normal observations [Table Six] had adverse outcomes meaning it is likely that no EWS will be $100 \%$ sensitive (i.e no children are falsely negative)

Table Six Number of observation for each Cardiff \& Vale PEWS score 


\begin{tabular}{|l|l|l|}
\hline $\begin{array}{l}\text { Cardiff and Vale } \\
\text { PEWS Score }\end{array}$ & \multicolumn{2}{l|}{ Number of sets of observations } \\
\hline & No adverse Outcome & Adverse Outcome \\
\hline 0 & 5746 & 9 \\
\hline 1 & 2338 & 16 \\
\hline 2 & 675 & 18 \\
\hline 3 & 168 & 23 \\
\hline 4 & 46 & 8 \\
\hline 5 & 15 & 7 \\
\hline 6 & 4 & 1 \\
\hline 7 & 0 & 0 \\
\hline 8 & 1 & 0 \\
\hline Total score 1 or more & 3247 & 73 \\
\hline Total observations & 8993 & 82 \\
\hline
\end{tabular}

Source: Edwards ED, Powell CVE, Mason BW, et al. Prospective cohort study to test the predictability of the Cardiff and Vale paediatric early warning system. Arch Dis Child 2009;94(8):602-606 [25]

As well as these systems which have been peer reviewed (but not necessarily validated) there are a variety of non-published scoring systems already in use across the UK. This profligation may demonstrate their use becoming more widely welcomed. However there is no one system that is universally favoured and the thorny issue of proving benefit continues to be an issue[27]. The lack of standardization in charts may indicate that departments or trusts were not keen on using systems borrowed or derived from others. The need to adjust, refine and test any system in its place of practice (regardless of its validation elsewhere) is supported by implementation theory[28]. It would be rational to suppose the introduction of an outside system into an unfamiliar environment is going to be fraught with difficulty. These problems with implementation and engagement had led the NHS Modernisation Agency to stipulate the positives and negatives of Track and Trigger systems (Table Seven)

There is also the particular problem of which actual measures should be used in the score. In the last survey of EWS 36 different physiological and observational parameters were used[6]. There is already wealth of information on individual parameters prediction of serious illness. In a large cohort of febrile children presenting to a Childrens Emergency Department in Sydney, Australia there was evidence that "..for all serious bacterial infections, appearing generally unwell was the strongest diagnostic marker, with raised temperature, no fluid intake in the previous 24 hours, increased 
capillary refill time, and chronic disease also predictive[29]". A smaller study in the UK, also based in an Emergency Department but prior to the introduction of the pneumococcal vaccine demonstrated developmental delay, risk factors for infection, alertness, level of temperature , capillary refill time, hydration status, respiratory rate and hypoxia to be relevant in the construction of a predictive model[29]. These studies and others indicate certain physiological, behavioural and background parameters maybe more beneficial than others in identifying illness. The studies producing this data tend to be aimed at identifying unwell children. An early warning score, because it is being utilised in an already unwell child, needs to identify relevant changes in parameters as well as the relevance of the individual parameter in its own right. A study looking at change in parameter against deterioration has not yet been formally performed.

\section{Table Seven}

Track and Trigger Scoring Systems (Modernisation Agency 2003)

\begin{tabular}{|l|l|}
\hline \multicolumn{1}{|c|}{ Positives } & \multicolumn{1}{c|}{ Negatives } \\
\hline $\begin{array}{l}\text { - Improve the quality of patient observation } \\
\text { and monitoring }\end{array}$ & - Are not a predictor of outcome \\
- Improve communication within the & Are not a comprehensive clinical \\
multidisciplinary team & - Are not an indicator for immediate \\
- Allow for timely admission to intensive & admission to intensive care \\
care & - Should never replace clinical judgement \\
- Aid good clinical judgement & \\
- Aid in securing appropriate assistance for \\
sick patients \\
- Give a good indication of physiological \\
trends \\
- Area sensitive indicator of abnormal \\
physiology \\
- Are a red flag marker of potential or \\
established critical illness
\end{tabular}

Source: Department of Health and Modernisation Agency. The National Outreach Report [12]

Finally there is the difficulty in defining serious illness in the context of a deteriorating child. For example a positive culture of an invasive microbiological organism is a reliable outcome measure. Asthma, renal or heart disease may also result in serious illness but grading the extent of severity is more difficult. Admission to paediatric high dependency or critical care area is often used in these cases as a surrogate measure of a child's illness. However increased frequency of medical review, medications, fluids or other interventions may also be a marker of quality of care and safety. 
Being able to predict which children will go onto to develop illness of sufficient severity to be admitted to intensive care areas may enable treatment to be commenced earlier and therefore prevent admission and is the raison d'etre of EWS. However developing such a model based on individual parameters is problematic across different disease processes and types of hospital (for example if you don't have an on-site intensive care unit). The heterogeneity of previously published studies has limited the comparison of smaller versus larger hospitals. It would be reasonable to hypothesise that larger units may support response teams with greater skills thus improving outcomes. However this is also dependant on the action instigated by activation of the EWS being timely enough to prevent deterioration. The time-point of intervention is rarely recorded but may significantly imbalance the reported performance of a score[23].

\subsection{Systematic Review}

The collation of available evidence on early warning scores has been difficult due to the very heterogenous nature of the research and the problems described above. A systematic review of the field was carried out in 2010 by Chapman and colleagues[7]. This body of work identified only eleven papers meeting the inclusion criteria of: research describing the development, testing or use of an EWS or activation of a MET in children hospital's outside of a critical care setting. The study confirmed the diversity of criteria used and commented on the low rate of studies examining interrater reliability in using the scores (which was only performed in one study). It is known the examination of key clinical signs differs according to both the sign itself[31] and the experience of the examiner[32]. Chapman et al. concluded that, "The potential of PACs (EWS and METs) to improve the care of hospitalised children by aiding earlier identification of those at risk of critical deterioration and thereby improved outcome has not, as yet, been demonstrated." An alternative reflection could be that no harm has been demonstrated by these studies and given the biological plausibility that EWS should identify at least some patients prior to collapse their use should be recommended. A previous literature review on Paediatric Rapid Response systems highlighted this point. Although the authors felt the downside of unvalidated systems maybe to increase admissions to intensive care they believed there maybe a total reduction in actual bed days[33]. Not included in the systematic review was a large multinational study looking at EWS which has been published recently[34]. This study found that a beside PEWS (which had previous been published) was able to distinguish "sick" (those patients admitted unexpectedly to an intensive care unit) from "well" in-patients with at least one hours notice. This is the first study in which a score has been validated across sites ( 4 university hospitals in this case). Although the study was prospective the authors noted the data collected was routine observations and the staff involved were not aware of the Bedside PEWS system and its component items (heart rate, systolic blood pressure, capillary refill time, respiratory rate, respiratory effort, transcutaneous oxygen saturation and oxygen therapy). This meant that the data was not identical for the case and control patients. Interestingly in the 23288 hours studies only $5.1 \%$ of patients had all seven items recorded.

\subsection{The future of EWS}

EWS are increasing in use, are recommended by national reports and appear to predict deterioration in a subset of patients. However the difficulties in validation have made a 
robust evidence base difficult to demonstrate. For those groups currently using EWS a reflection on the role it is playing and how effective it is maybe necessary. For those interested in introducing a system it may be pragmatic to consider the following [Table Eight]

\title{
Table Eight
}

\section{Considerations prior to introduction of an EWS}

\author{
1. What is the patient group the EWS will be used on? \\ 2. What outcome are you looking to alter? \\ 3. What type of EWS would you like to introduce? \\ 4 Is there a current system you could employ? \\ 5. How will you engage and be responsive to the concerns of the stakeholders? \\ 6. How will you monitor its effect?
}

The NHS Institute for Innovation and Improvement have produced an information portal regarding EWS which provides information on implementing and assessing change

(http://www.institute.nhs.uk/safer_care/paediatric_safer_care/paediatric_safer_care.ht ml.)

It will be important for researchers to clarify the difference between illness identification systems at the "front door" to healthcare services and those used on inpatients although it may be possible, and in fact desirable, to combine systems to aid communication during the patient journey. A more fundamental question, given the difficulty in validating in different health care locations, and noting the potential educational benefits it provides, is whether the use of the system is more important than its outcome?

Given the financial pressures on healthcare services in the immediate future the costs of implementing EWS must be defined. This however is difficult as little of the development, implementation and outcomes are fixed quantities. Education and training of staff, for example, occurs over time due to the fluid health care workforce. Maintaining engagement and uptake requires staff with named EWS responsibilities but this varies on the size of department. Savings, such as reduced stays on PICU, may be easier to classify but determining an absolute reduction in days will to some extent be connected to whether the unit is on or off site. Litigation costs vary hugely and although protecting against one child with long term disability as a result of failed recognition of septicaemia is a persuasive emotional argument to commissioners it is harder to judge a true financial burden. Calls for national initiatives to examine these issues including the need for collaboration between the major organistions involved with child health such as the Royal Colleges of Paediatrics and Child Health (RCPCH) and Care Quality Commission have already been made [35]. 


\section{Conclusions}

A number of EWS are available, some published and some not. Strict methodological assessment would indicate there is a lot of work still to be done in proving their benefit. However it is important, for the safety and health of children, that mechanisms exist to be able to recognise and respond to the potentially deteriorating child in any health care setting. National guidance suggests that these mechanisms must be established. There may be no one type of EWS that can effectively and efficiently do this given the range of different health care settings and patient acuities that exist. An ideal EWS may in fact be one that is locally derived but based on previous positive (and preferably validated research), which has engaged staff and delivers on designated outcomes .

Competing interest: Dr. Roland is in receipt of an East Midlands HIEC grant to develop POPS (paediatric observation priority score) for three children's emergency departments.

Funding: This report is independent research arising from a Doctoral Research Fellowship supported by the National Institute for Health Research. The views expressed in this publication are those of the author and not necessarily those of the NHS, the National Institute for Health Research or the Department of Health

\section{References}

1. Tume L. The deterioration of children in ward areas in a specialist children's hospital. Nurs Crit Care 2007;12(1):12-19.

2. Pearson G. Why Children die: a pilot Study 2006, England (South West, North East and West midlands), Wales and Northern Ireland. 2008;1.

3. Review of patient safety for children and young people. 1st ed. London: National Patient Safety Agency; 2009.

4. NICE. Acutely ill patients in hospital: Recognition and response to acute illness in adults in hospitals. 2007.

5. National Outcomes Framework Technical Annex. http://www.gpcwm.org.uk/wpcontent/uploads/file/A-

Z\%20DOWNLOADS/N\%20DOWNLOADS/NHS_Outcomes_Framework_2012_13_D0H_7_ December_2011.pdf (last accessed 14th March 2012)

6. Duncan HP. Survey of early identification systems to identify inpatient children at risk of physiological deterioration. Arch Dis Child 2007;92(9):828-828.

7. Chapman SM, Grocott MP, Franck LS. Systematic review of paediatric alert criteria for identifying hospitalised children at risk of critical deterioration. Intensive Care Med 2010;36(4):600-611.

8. McCarthy PL, Sharpe MR, Spiesel SZ, et al. Observation scales to identify serious illness in febrile children. Pediatrics 1982;70(5):802-809. 
9. Van den Bruel A, Haj-Hassan T, Thompson M, et al. Diagnostic value of clinical features at presentation to identify serious infection in children in developed countries: a systematic review. Lancet 2010;375(9717):834-845.

10. Morley CJ, Thornton AJ, Cole TJ, et al. Baby Check: a scoring system to grade the severity of acute systemic illness in babies under 6 months old. Arch Dis Child 1991;66(1):100-105.

11. Buist MD, Jarmolowski E, Burton PR, et al. Recognising clinical instability in hospital patients before cardiac arrest or unplanned admission to intensive care. A pilot study in a tertiary-care hospital. Med J Aust 1999;171(1):22-25.

12. Department of Health and Modernisation Agency. The National Outreach Report 2003. 2003;1.

13. Royal College of Physicians. Acute Medical Care. The right person, in the right setting - first time. 2007.

14. Roland D and Coats T. An Early Warning? Universal Risk Scoring in Emergency Medicine. Emerg Med J 2011;28(4):263

15. Monaghan A. Detecting and managing deterioration in children. Paediatr Nurs 2005;17(1):32-35.

16. Sinitsky L, Dilks C:, A. The PAWS score and the need to consider oxygen requirement. (Response to The PAWS score: validation of an early warning scoring system for the initial assessment of children in the emergency department Emerg Med J 2008;25:745749). Emergency Med J 2008(Online).

17. Tibballs J, Kinney S, Duke T, Oakley E, Hennessy M. Reduction of paediatric in-patient cardiac arrest and death with a medical emergency team: preliminary results. Arch Dis Child 2005;90(11):1148-1152.

18. Brilli RJ, Gibson R, Luria JW, Wheeler TA, Shaw J, Linam M, et al. Implementation of a medical emergency team in a large pediatric teaching hospital prevents respiratory and cardiopulmonary arrests outside the intensive care unit. Pediatr Crit Care Med 2007;8(3):236-46; quiz 247.

19. Tibballs J. Systems to prevent in-hospital cardiac arrest. Paediatrics and Child Health 2011; 21(7): 322-328

20. Joffe AR, Anton NR, Burkholder SC. Reduction in Hospital Mortality Over Time in a Hospital Without a Pediatric Medical Emergency Team: Limitations of Before-and-After Study Designs. Arch Pediatr Adolesc Med 2011;165(5):419-423.

21. Ferguson S, Stark M, Madar J. Paediatric Early Warning System (PEW) - a model for improved recognition and management of the critically ill. Arch Dis Child 2003;88(suppl 1):A30-A32.

22. Haines C, Perrott M, Weir P. Promoting care for acutely ill children-Development and evaluation of a Paediatric Early Warning Tool. Intensive and Critical Care Nursing;22(2):73-81. 
23. Duncan H, Hutchison J, Parshuram CS. The Pediatric Early Warning System score: a severity of illness score to predict urgent medical need in hospitalized children. J Crit Care 2006;21(3):271-278.

24. Livingstone H, Whiteley S, Luntley J. Development of a Paediatric critical illness early warning score: The Paediatric Advanced Warning Score. Arch Dis Child 2005;90(Suppl II):A33-A38.

25. Edwards ED, Powell CVE, Mason BW, et al. Prospective cohort study to test the predictability of the Cardiff and Vale paediatric early warning system. Arch Dis Child 2009;94(8):602-606.

26. Edwards ED, Mason BW, Oliver A et al. Cohort study to test the predictability of the Melbourne criteria for activation of the medical emergency team. Arch Dis Child 2011;96(2):174-9

27. Tibballs J, Kinney S. Evaluation of a paediatric early warning tool--claims unsubstantiated. Intensive Crit Care Nurs 2006;22(6):315-6; author reply 317.

28. Langley GL, Nolan KM, Nolan TW, et al.The Improvement Guide: A Practical Approach to Enhancing Organizational Performance. 2nd ed. San Francisco: Jossey Bass; 2009.

29. Craig JC, Williams GJ, Jones M, et al. The accuracy of clinical symptoms and signs for the diagnosis of serious bacterial infection in young febrile children: prospective cohort study of 15781 febrile illnesses. BMJ 2010;1;340.

30. Brent AJ, Lakhanpaul M, Thompson M, et al. Risk score to stratify children with suspected serious bacterial infection: observational cohort study. Arch Dis Child 2011;96(4):361-367.

31. Steiner MJ, DeWalt DA, Byerley JS. Is This Child Dehydrated? JAMA:2004;291(22):2746-2754.

32. Roland D, Clarke C, Borland ML et al. Does a standardised scoring system of clinical signs reduce variability between doctors' assessments of the potentially dehydrated child? J Paediatr Child Health 2010;46(3):103-107.

33. Winberg H, Nilsson K, Aneman A. Paediatric Rapid Response Systems: a literature review. Acta Anaesthesiol Scand 2008;52(7):890-896.

34. Parshuram CS, Duncan HP, Joffe AR et al. Multi-centre validation of the Bedside Paediatric Early Warning System Score: A severity of illness score to detect evolving critical illness in hospitalized children. Crit Care 2011;15(4):R184.

35. Pearson G and Duncan H. Early warning systems for identifying sick children. Paediatrics and Child Health 2011;21:5:230-233 